\title{
Profesionalización del tutor de postgrado II Encuentro Lazareto de Mahón, Septiembre 2004
}

\author{
Instituto de Salud Carlos III y Asociación de Redes Docentes y Asesoras
}

En el marco de la Escuela de Verano de Salud Pública se celebró los días 24 y 25 de septiembre el II Encuentro sobre la profesionalización del tutor de postgrado, en el que participaron representantes de las redes de docencia y asesoras de Cataluña, Madrid, Andalucía, Comunidad Valenciana, Galicia, Euskadi y Canarias, de las autonomías de Castilla La Mancha y Castilla León y de las comisiones de docencia y comisiones asesoras de Cantabria, y Navarra. A lo largo de los dos días se debatieron 5 temas de especial relevancia en la formación especializada llegándose a las siguientes conclusiones y recomendaciones para cada uno de ellos:

\section{I.-Valoración formativa}

\section{Conclusiones}

Hay que hacer una evaluación basada en el rigor metodológico y enfocada a la valoración formativa. La evaluación debe estar basada en los Programas Docentes y hay que disponer de medios para realizarla.

\section{Recomendaciones}

1. Hay que formar a los tutores en evaluación.

2. Se precisa disponer de tiempo para hacerla.

3. Hay que tener reuniones con los tutores.

4. Es necesario generar alianzas multi - institucionales para diseñar y poner en práctica proyectos sólidos de valoración formativa, con presupuesto concreto.

\section{II.- Tutela del residente en Urgencias}

\section{Conclusiones}

La tutela de Residentes en Urgencias es insuficiente. Los Servicios de Urgencias no están dimensionados adecuadamente, lo que es una causa fundamental de la falta de tutela. La realización de guardias en Urgencias es necesaria para la formación de los Residentes.

Recomendaciones

1. Los Servicios de Urgencias deben dimensionar adecuadamente su plantilla

2. Los órganos directivos de los hospitales deben implicarse activamente en la organización de los Servicios de Urgencias, en su funcionamiento y en el control de la tutela que reciben los residentes.

3. Deben desarrollarse programas docentes para la formación en Urgencias de los Residentes.

4. Durante las primeras fases de la formación debe existir una tutela directa, no siendo deseable la tutela localizada.

5. La tutela entre residentes es deseable siempre que no se realice para cubrir una plantilla insuficiente.

III.- Organización de Unidades Docentes

Conclusiones

Las Unidades Docentes (UD), elementos clave para la 
formación de especialistas, deben desarrollar la docencia de postgrado basándose en el desarrollo de los programas docentes de las especialidades así como procurar niveles de organización, gestión y calidad de excelencia. La labor docente debe quedar reflejada en resultados docentes medidos por indicadores docentes.

\section{Recomendaciones}

1. Hay que potenciar las UD considerando la docencia como parte estratégica del producto hospitalario, dotándola de tiempo y otros recursos para el desarrollo de los programas docentes.

2. El trabajo docente debe ser reconocido y acreditado.

3. Es necesario desarrollar y conseguir formación de los profesionales en metodología y gestión docentes.

\section{IV.- Programa común complementario}

\section{Conclusiones}

Existe una necesidad de formación en aspectos nucleares, imprescindibles y esenciales para la práctica sanitaria, no recogidos en los programas nacionales de las distintas especialidades, Las Comisiones de Docencia y Asesoras y sus redes deben promover actividades formativas en dichos aspectos, con el apoyo y la financiación de las instituciones autonómicas. Dichos aspectos formativos nucleares serán flexibles y dinámicos en la definición de sus contenidos. La realización de esta formación por parte de los residentes deberá ser reconocida formalmente por las Comisiones de Docencia y las Instituciones Sanitarias

\section{V.- Acreditación de tutores}

\section{Conclusiones}

La adecuada labor de los tutores es indispensable para el buen funcionamiento de los programas docentes de postgrado de los centros sanitarios siendo necesario el reconocimiento explícito de la labor tutorial como elemento de mejora de esos programas. Las vías de reconocimiento son diversas, pero prioritariamente tendrían que ser de tipo económico o de aumentar el tiempo de dedicación a la tutoría.

\section{Recomendaciones}

1. Reorganizar los servicios o unidades docentes para favorecer la labor tutorial.

2. Se deben arbitrar mecanismos para dotar a la figura del tutor de mayor relevancia dentro de los servicios o unidades docentes.

3. Además de los propios centros sanitarios, las administraciones públicas han de implicarse en el reconocimiento de la labor tutorial. 